2018-01-18

\title{
Elemental mobilities: atmospheres, matter and cycling amid the weather-world
}

\author{
Simpson, Paul
}

http://hdl.handle.net/10026.1/10613

\subsection{0/14649365.2018.1428821}

Social and Cultural Geography

Taylor \& Francis (Routledge)

All content in PEARL is protected by copyright law. Author manuscripts are made available in accordance with publisher policies. Please cite only the published version using the details provided on the item record or document. In the absence of an open licence (e.g. Creative Commons), permissions for further reuse of content should be sought from the publisher or author. 
Elemental mobilities: atmospheres, matter and cycling amid the weatherworld

\author{
Paul Simpson \\ School of Geography, Earth, and Environmental Sciences, University of Plymouth, Drake \\ Circus, Plymouth, PL4 8AA \\ paul.simpson@plymouth.ac.uk
}

The Version of Record of this manuscript has been published and is available in 'Social and Cultural Geography'. Published online on 19/12/18 at http://www.tandfonline.com/10.1080/14649365.2018.1428821.

Funding:

This research was funded by an RGS-IBG Small Grant

Acknowledgements:

Thanks to John Horton, the anonymous referees, Jon Shaw, and David Bissell for providing constructive comments on earlier drafts of this paper. Thanks also to Tim Absalom for assistance with producing the figures and to Nicky Harmer for assistance with data analysis. 


\begin{abstract}
Everyday experiences of movement have become a central concern for social and cultural geography in recent years. Work here has begun to unpack the specific meanings, imaginaries, and experiences that come to be bound up with mobile bodies and their practices. However, it has been suggested that more could be done to examine the material, elementary, molecular and physical aspects of movement which are significant to the experience of being on the move. Therefore, this paper explores the experience of cycling amid such turbulent 'elemental' materialities. Such 'matters' matter to cycling in the way that they (re)make both mobile environments and mobile subjectivities. Cyclists come to have quite immediate and intimate relationships with the material and 'elementary' aspects of the environments they move through given their relatively unmediated encounters with them. This paper draws on video-interview based research with 24 commuter cyclists in Plymouth, UK to consider cyclists' experience of atmospheric conditions in terms of air's force and air quality. From this the paper reflects on how the experience of such 'elemental' matters might be significant to future research on and planning for cycling.
\end{abstract}

Keywords: Atmosphere, Cycling, Materiality, Mobility, Video-interview, Weather.

\title{
Introduction: Getting things off the ground
}

In the spring of 2016 Plymouth Cycle Campaign unveiled ambitious plans to address issues with existing transport connections between Plymouth's city centre and key residential areas to its north. The specific challenge: how to get cyclists across a deep valley that traverses the northern edge of the city centre and through which runs the main railway line that connects the majority of the country (to the east) with Plymouth and Cornwall (to the west). The combination here of changing relief and the congested nature of the main crossing points either over or under the railway line are considered by many as obstacles to increasing cycling participation. Further, these routes fall within an Air Quality Management Area where Nitrogen Dioxide levels exceed national government objectives (Plymouth City Council, 2016). They are by no means pleasant environments to move through. The solution: a cycle bridge that would span the railway line from Central Park (a large green space to the north of the railway line) to the northern edge of North Cross Roundabout (Figure 1). In the Campaign's own words, such a bridge "will link the busy centre of Plymouth with the 'green lung' of Central Park and provide a commuting and recreational route for a wide spread of residential areas" (Plymouth Cycle Campaign, n.d.). This would take cyclists out of the undulating, congested, and dirty routes currently available and lift them up into the open. 
Figure 1 'Two options for the proposed pedestrian-cycle bridge'

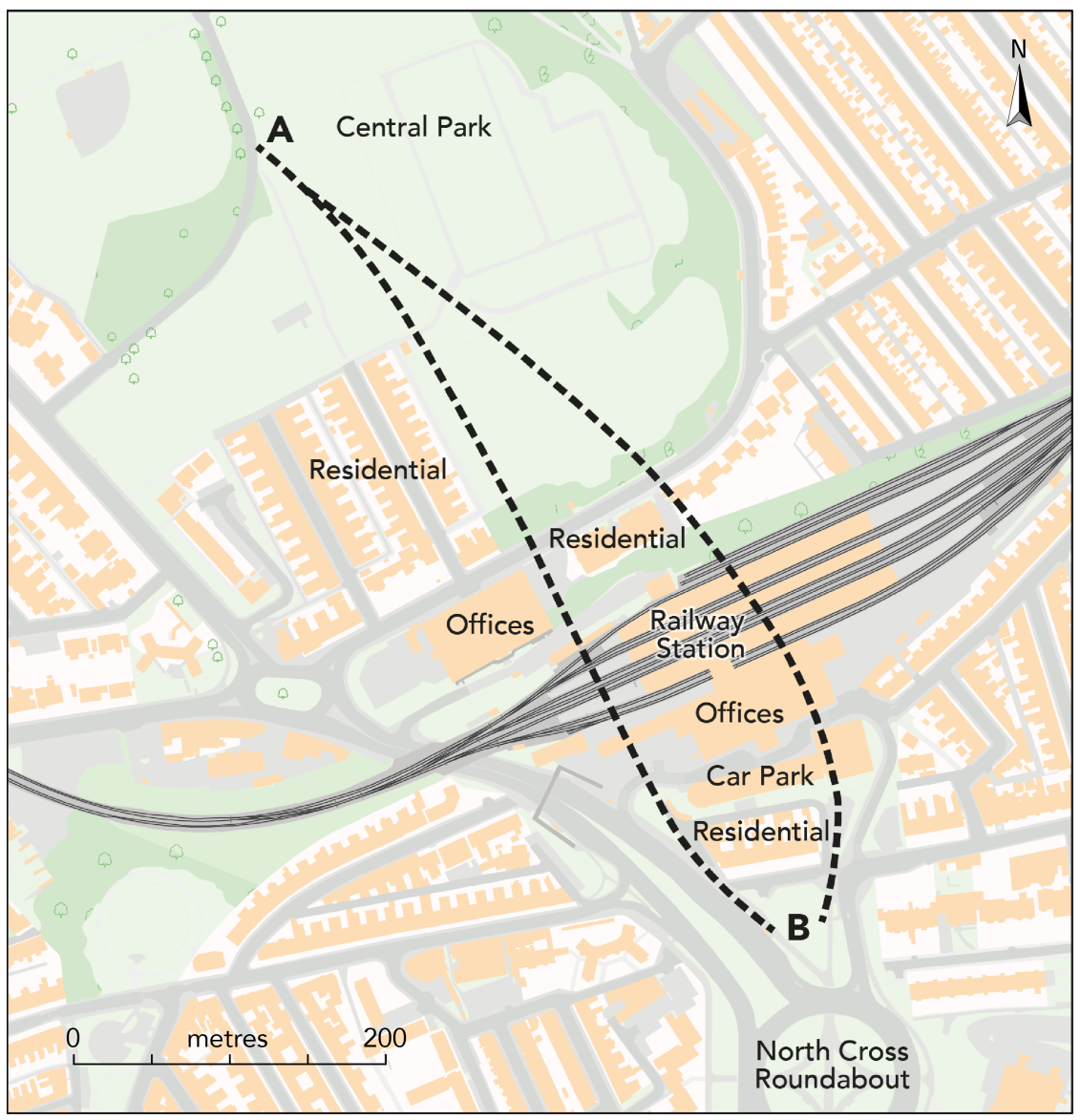

While overpasses are not an especially unusual transport solution in the UK there are some notable features of this proposal (Figure 2). Each option for the overpass spans approximately $600 \mathrm{~m}$. The elevation change between the start / end points to the base of the valley is $20-30 \mathrm{~m}$ (not taking into account the bridge's own rise above those points). Further, the overpass would run over or past the rooftops of a range of residential and commercial premises, public roads and pavements, an area of allotment gardens, as well as Plymouth's main train station itself. The Cycle Campaign did not provide an estimate for the cost of the project but the above factors suggest that this would be significant.

This proposal immediately poses a range of questions around its practicality and suitability as an infrastructural solution that effectively deals with the challenging combination of physical geography, air quality, urban form, and transport infrastructure present here. For example, questions have been asked by local residents about the potential for planning objections from the tenants of the commercial and residential properties underneath / alongside the overpass. Safety has also been raised as a concern for both those on and below the bridge. 
Figure 2 'Transact of the proposed pedestrian-cycle bridge'

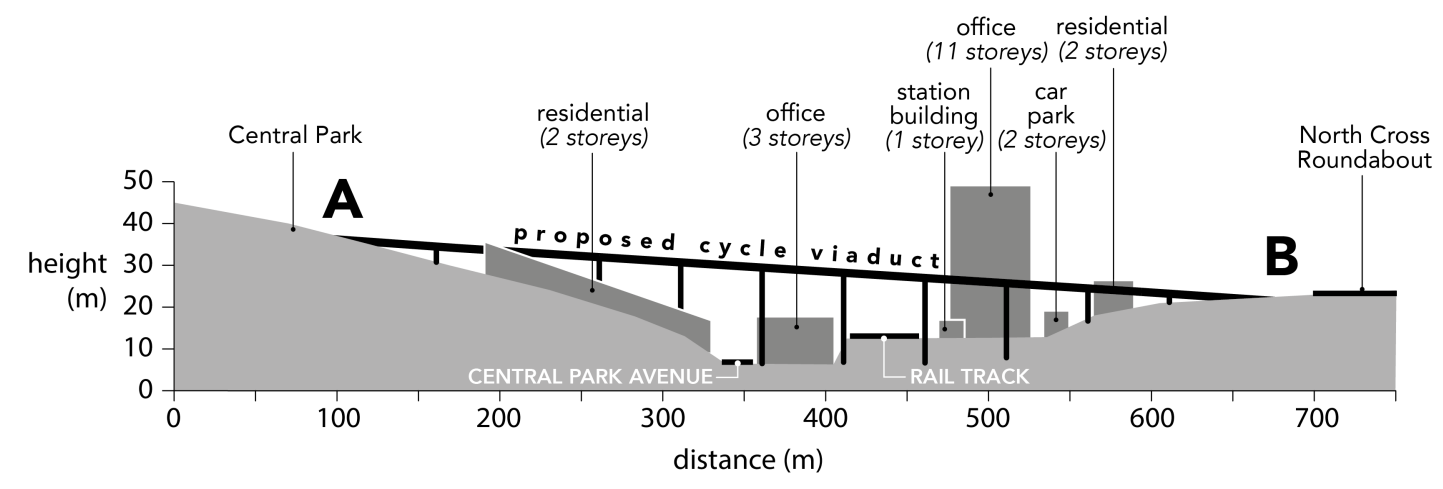

Concern has been expressed over usage compared with other routes and so how much value for money this proposal would provide. And relatedly, many have asked: what else could that money (if available) be used for in the city to develop / maintain / improve the existing (relatively limited) cycle provision? ${ }^{1}$

Amongst these debates, one critical comment from a local resident stands out in terms of its point, or rather volume, of reference. Rather than being concerned with issues of cost or urban planning, this comment instead considered Plymouth as a specific environmental context to move through. The comment was simply: "wouldn't want to walk over that when there's 50mph winds". This could be read as a fairly banal and obvious observation - being by the coast in the South West of England means that Plymouth is a windy city. ${ }^{2}$ Here turbulent air is less an occasional disorganizing force or event that gets in the way of normal smooth travel (Cresswell \& Martin, 2012), and is more a simple fact of the environmental context Plymouth presents; variously turbulent air is a common feature of the circadian and seasonal rhythms of the weather systems that move through Plymouth.

Certainly, adverse weather conditions and their impacts upon travel behaviour have been considered at some length by transport scholars (see Böcker et al, 2013). However, the reader's comment about strong wind mentioned above does also suggest a certain sensibility that draws attention to the experience of travel, to what it means to inhabit such an environment (Ingold, 2008). This might be a less obvious starting point from which to debate proposed changes in transport infrastructure provision and improvement than those discussed above. Nonetheless, projecting cyclists this far up into the sky above a valley in a coastal city draws attention to a fundamental aspect of cycling both here and in general: that it often entails moving through variably turbulent air. Once that is realized, a number of quite 
logical questions emerge: 1) what will it actually be like to cycle through the sky in a windy city like Plymouth? 2) more generally, what does this turbulent medium do to cyclists and the environments they move through when it comes to more mundane existing forms of infrastructure? and, 3) what is it like to cycle amid those congested, dirty, and particle-laden spaces this bridge seek to bypass in the first place?

A concern for various experiential aspects of mobility are now well established in social and cultural geography (Adey et al, 2014). Research has begun to unpack the specific meanings, imaginaries, and experiences that come to be bound up with cyclists and their practices (Skinner \& Rosen, 2007). This has included a particular focus on cyclists' identities (Aldred, 2010; 2012; 2013a; 2013b), their experiences of the landscapes they move through (Spinney, 2006; 2007), and the troubling affective experiences that can arise in moving through urban environments (Jones, 2005; 2012). However, Merriman (2012, p. 9) has suggested that more could be done to examine how "the material, 'elementary', molecular and physical aspects" of movement are significant to the affective and experiential qualities of being on the move. As the opening case of Plymouth's proposed pedestrian-cycle overpass suggests, while mediated by various forms of technology, cyclists can come to have quite immediate and intimate relationships with the material and 'elementary' aspects of the designed environments they move through, whether that be in terms of winds that buffet them or fumes that permeate them.

Therefore, this paper explores the experience of cycling amid such turbulent 'elemental' materialities. The argument here is that such environmental circumstances matter to cycling in the way that they make and remake both mobile environments and mobile subjectivities / experiences. This argument is developed in relation to three interrelated sets of debates relevant to the social and cultural geographies of practice and mobility. Firstly, the paper moves beyond the sorts of approaches taken by recent transport scholarship which considers atmospheric conditions like weather as factors that simply impact upon decisions to travel or not (see Böcker et al, 2013). This paper shows atmospheric conditions to be something that come to be bound up with, and so impact upon, both the experience of being on the move and the perception of the environments moved through (Ingold, 2015; Vannini et al, 2012). Secondly, the paper further develops recent work in social and cultural geography that questions geography's elemental prejudices and related conceptions of materiality (Jackson \& Fannin, 2011; Anderson \& Wylie, 2009). An attentiveness to atmospheric 
circumstances expands the material realm to include more turbulent, molecular matters matters that we both move through and that move through us - that have a bearing on experiences of being on the move (Merriman, 2012; McCormack, 2007). Finally, through the combination of these points, the paper refines existing conceptual approaches to such atmospherics by considering together their meteorological, affective, and social-situated nature. Thus far, work on atmospheres has tended to think through these relatively separately (or not at all) rather than considering, for example, the implications of the meteorological and the affective or how either of these emerge from within, and so are influenced by, specific social circumstances (Ingold, 2015; McCormack, 2008). This will all be advanced throughout a discussion of video-interview based research with 24 commuter cyclists in Plymouth, UK which reflected upon cyclists' experience of cycling amid various transport infrastructures and environmental circumstances.

The remainder of the paper unfolds as follows. The next section elaborates on Merriman's call for a more elemental focus by looking to recent literature in geography, anthropology and architecture that is concerned with various forms of atmosphere and materiality. The following section outlines the empirical research that the paper draws upon. From there, the next two sections discuss cyclists' experience of atmospheric conditions in terms of air's force and air quality, respectively. The conclusion reflects on how the experience of such 'elemental' matters might be significant to future research on and planning for cycling.

\section{Elemental matters and the weather-world}

Many forms of mobility entail envelopment in a bubble of glass and steel. These often come with specific sensory experiences and technologies of air-conditioning (Slotedijk, 2009). However, cycling entails a relatively unmediated relationship with the environment moved through. Cyclists are usually clothed, often wear various forms of safety equipment, and potentially use other mobile technologies that all mediate their interactions with their environments (Spinney, 2007). Nonetheless, cyclists are generally more open to the environment than many other road users. Rain and wind, for example, have much more immediate impacts on the cyclist's body than that of most motorists (Parkin et al, 2007) and the sounds and smells of the city can be much more immediately present to them (Jungnickel \& Aldred, 2014). 
Transport research has considered cyclists' exposure to the environments they move through in a number of ways. Most evidently, the impact of both everyday and seasonal variations in weather conditions on cyclists' travel behaviour (i.e. if, where and / or when they cycle) has been examined through the use of travel diaries (Böcker et al, 2013). This often compares objective weather data records for precipitation, temperature and wind with this travel diary data. Equally, some specific geographic considerations have also featured within this in terms of how such impacts of weather on travel behaviour might vary according to differences in urban form or through the presence of micro-climates (Helbich et al, 2014). Such transport scholarship, though, hasn't necessary considered how such "'elementary geographies' of the passage....are important to the particular qualities and experiences of movement" (Merriman, 2012, p. 9). The focus has tended thus far to be more around travel behaviour and decision making - again, if, how and when to travel - rather than the experience of moving in and through such weather. Even when attention does touch on cyclists' experience of their environments (Böcker et al, 2015), this has primarily entailed quantitative analyses of the impact of weather on cyclists' aesthetic appreciation of the environments moved through and not their embodied interactions with them. This means that such transport scholarship has tended to reduce the experience of weather to a binary position around whether people travel or not given certain weather conditions. This loses sight of the richness and variety of experiences cycling in various weather conditions can elicit and, with that, the impact that this can have of the perception of the environments moved through.

Mobilities scholars, though, have also not necessarily engaged with such 'elemental' aspects of movement as much as they might have. While a range of facets of movement have been discussed in light of the mobilities turn, such discussions have been based on certain "elemental prejudices" (Jackson \& Fannin, 2011, p. 435; though see Adey, 2014; 2015; Cresswell \& Martin, 2012; Martin, 2011). How movement becomes meaningful and entails embodied interactions with places, landscapes, routes, infrastructures, mobile technologies, and so on has tended to dominate in such literature. It has only really been when such elemental materialities become too pressing to ignore - such as in the case of the 2010 volcanic ash cloud and subsequent large-scale disruption to transatlantic travel (Adey et al, 2011) - that they have received more substantive attention. This relative absence of 'elemental' discussions is mirrored in the broader social science literature on experiences of 
dwelling and practice-based discussions of human-environment relations which has focused more on people's inhabitation of and interaction with 'thingly' materialities (Ingold, 2015).

Such elemental prejudices and their subsequent blind spots can be interrogated in at least two ways.

Firstly, while a range of work has emerged on atmospheres within literature on everyday and mobile practices (see Adey et al, 2013), this has been more aesthetic than climactic in orientation (for some exceptions see Adey, 2014; McCormack, 2008; Vannini et al, 2012). The focus in such work has largely been on atmospheres in their affective sense (Bohme, 2016), being taken to refer to "something distributed yet palpable, a quality of environmental immersion that registers in and through sensing bodies while also remaining diffuse, in the air, ethereal" (McCormack, 2008, p. 413). Meteorological atmospheres, relating to that "turbulent zone of gaseous matter surrounding the earth and through the lower reaches of which human and non-human life moves", have been less prominent in such discussions (McCormack, 2008, p. 413). The sorts of discussions of catastrophic events mentioned above aside, "For many scholars, aerodynamics, gravity, light, buoyancy, texture, friction, weather systems or vibrations may be too banal, physical or perhaps 'unsocial' to include in accounts of mobility systems" (Merriman, 2012, p. 9).

Translating this back into the specific context of cycling, one of the significant features of the experience of cycling, and so the folding together of the affective and the meteorological, is the way in which cyclists are exposed to what Ingold (2007) calls 'the weather-world'. For Ingold, talking in terms of the weather-world draws attention to the ways in which we do not just relate to other objects or entities on the earth's surface. Rather than moving across such surfaces as 'exhabitants' of the world, we are immersed in a turbulent medium - the atmosphere / air - in and through which such relations play out. In this sense, "the weather in which one stands can be as much responsible for generating a sense and use of place as the ground on which one stands" (Pillat cited in Veale et al, 2014, p. 26). In being amid this weather-world, "Weather constantly makes and remakes place" (Vannini et al, 2012, p. 364) and the subjectivities than inhabit them. Or as Saito (cited in Böcker et al, 2015, p. 129) puts it in discussing wind:

"Our experience of a fierce autumn is not simply the feeling of wind against our body; the way in which fallen leaves swirl around, the dynamic swaying of tree branches, the rustling sound they make, the slightly musty smell coming from half-decaying leaves accumulated 
on the ground, and the rapid movement of clouds all contributes toward our experience of this windy weather".

Secondly, such elemental prejudices manifest in the limited attention paid to the molecular materiality that often unfolds below the level of our routine sensory engagement with the world - for example, the microscopic particles of rotting leaves suspend in and communicated through the windy weather-world discussed above which allow us to 'smell the leaves'. While there have been a range of calls to 'rematerialise' human geography and so ground discussions in a tangible reality of thingly stuff (see Anderson \& Wylie, 2009), much of the non-human materiality circulating amid our relations with the worlds we inhabit takes place at a molecular level that forms a "material substrate of affective experience" (McCormack, 2007, p. 360). Returning to the opening overpass proposal, part of the issue there lay in the concentration of harmful particulate matter (NO2) in the existing routes (not to mention the soot-blackened walls that line a number of them). Here the human body's relations with non-human materiality extend beyond the specific discrete 'things' we can immediately see, touch, or perceive.

While it may be suggested that such micro-scale materialities exist beneath the threshold of human perception and therefore do not directly matter to the experience of movement here, such a position misses at least two points. Firstly, while they may not appear to us as clearly as other more transparently thingly phenomena (in the context of cycling, objects like buses, kerbs, painted lines, signage, and so on), they can still act upon us at an embodied level and so play a part in how those experiences come to pass, just in ways that we aren't always immediately or entirely aware. While we might not see or realize that we're moving amid high concentrations of pollen on a summer's day, if someone suffers from hayfever they may well still end up fatigued, rubbing at their eyes, or with an itchy throat. Secondly, in certain circumstances such materialities are something of which we can become aware. At times they affect us in such a way as to draw attention to their action upon us. They might manifest with such volume or concentration that they find sufficient consistency for us to realize that they are in fact present. For cyclists, this might happen as we choke on a particularly voluminous cloud of exhaust fumes that appears in our path from the back of an old diesel trade vehicle or when we remove a dirty carbon mask at the end of a commute. Equally, our attention might be drawn specifically towards their presence (or absence) by some external agency. Again for cyclists, that might be due to the designation of 
a particular street as falling within an Air Quality Management Area (as in the overpass proposal), being surround by signage related to congestion charging, or as a result of seeing the advert on the side of a newer bus stating that it is using clean / hybrid technologies.

Based on this, Ingold suggests that if we start to think more about the materiality of the medium that is inhabited and moved through here, the orientation of the analysis needs to shift. As Ingold notes:

"To understand how people can inhabit this world means attending to the dynamic processes of world-formation in which both perceivers and the phenomena they perceive are necessarily immersed. And to achieve this we must shift our attention from the congealed substances of the world, and the solid surfaces they present, to the media in which they take shape, and in which they may also be dissolved" (2007, p. S28).

It is important to note, though, that such movement amid various turbulent materialities is not a-social and we need to be careful not to entirely shift our gaze from such congealed surfaces. As mobilities scholars have recently begun to unpack, such micropolitical concerns are entangled with and co-emerge from more macropolitical situations (Bissell, 2016). Movements very much happen within a specific social-cultural-political context and upon specific, often designed / engineered, materialities.

In the context of cycling again, movement evidently happens across various forms of planned transport infrastructure, such as a cycle path, which are products of various socialcultural-political contexts and transport cultures (Aldred, 2012). Such infrastructure holds capacities to affect those making use of it given the ways that it acts to "broker interactions between people, between things, between people and things" (Tonkiss, 2015, p. 384-385). They also shape, and are shaped by, such atmospheres. These surfaces (and any formations on / of them) are then perpetually emerging, forming, and deforming. Such surfaces do evidently hold a degree of consistency within that and variously resist the forces that are exerted on them. But also, the human-made formations that furnish them - here, traffic islands, cycle paths, speed bumps, and so on - do come to be as part of the environment through human and physical processes that act upon them, often across various slow / long durations. Just think of potholes that grow through freeze-thaw actions or faded paint lines whose pigment gradually erodes as a result of innumerable footsteps falling upon them. This mediating-mediated situation of cycling infrastructure raises an important point regarding the way we understanding the relations that occur amongst cyclists, other road users, and the various forms of materiality they encounter (Latham \& Wood, 2015; Simpson, 
2017). Any experience of atmospheric materialities will always also be situated within a specific planned, built environment and their interactions contribute towards how the experience of movement comes to unfold for a cyclist.

Therefore, in this paper the aim is to consider the co-implications of the affective, the meteorological, the molar and the molecular and so to recognize how "our affective lives are carried in the air" (Ingold, 2015, p. 80) at the same time as along the ground. In thinking about cyclists' experiences of movement, the paper will seek to move beyond a phenomenology of 'stuffness' (Jackson \& Fannin, 2011) and with that recognize that "matter potentially takes place with the capacities and properties of any element (ie earth, wind, fire, air) and / or any state (ie solid, liquid, gaseous)" (Anderson \& Wylie, 2009, p. 319). The concern is very much with how "these material qualities and events [encounters with turbulent air, fumes, and so on] are key components of our experiences of mobility as well as being of central importance in the engineering of these mobilities" (Merriman, 2012, p. 9). The focus will be on how atmospheric conditions and the molecular materiality they mobilize are both contextual and affective and so how mobile subjectivities and the environments they move through are ongoing accomplishments affected by numerous materialies and their encounters with them.

\section{Researching cyclists' experiences}

Researching something as banal as cyclists' everyday experiences of moving amongst weather and other micro-scale materialities is not a straightforward task. These are very much background phenomena routinely encountered that may well receive less immediate consideration compared with, for example, the occasional yet more dramatic events that cyclists sometimes encounter in their movements through urban environments - near misses with traffic, hostile acts of motorists, dangerous maneuvers, and so on (Jones, 2005). In response, the research here employed a video-interview approach with 24 commuter cyclists $^{3}$ in Plymouth, UK who were recruited through a range of gatekeeper organizations (including Plymouth Cycle Campaign and Bike User Groups from Plymouth University, Plymouth City Council, and the Marine Biological Association) as well as personal contacts / snowballing. The video-interviews entailed these cyclists undertaking their usual commutes to and / or from their place of work wearing a headcam. The video this produced was used to develop an interview schedule for each participant that discussed his or her everyday 
experiences of cycling in the city. The interviews themselves entailed watching selections of the participant's video and discussing points that the video raised for the researcher or which the participants wanted to discuss. There was also more open discussion about the participants' experiences not recorded on video. Participants recorded on average one hour of video - ranging from a single journey to four 10-15 minute journeys - and interviews also lasted for approximately one hour.

This video did not capture all aspects of cyclists' experiences of the environments they moved through. You can't necessarily see, for example, the wind blowing or how the affects brought about were felt in cyclists' bodies. However, this approach did facilitate reflection upon such background phenomena as they were encountered during cyclists' journeys. The video was employed precisely to retain "some of the context and detail of the practices under scrutiny whilst allowing the researcher to talk through [such] practices 'as they happen' during playback with participants" (Spinney, 2011, p. 166). This allowed for some reflection on the less abrupt, the less spectacular, but still pressing encounters cyclists had with various forms of materiality in their movements. At the same time, this also means that much of what follows may appear to be quite banal or, at first look, not especially worthy of note. But that should not mask the extent to which such encounters do matter; their ubiquity, their frequency of occurrence, and the routineness they acquire as a result demonstrate their very significance. They are so routine that they are often forgotten when it comes to considerations of cycling experience or debates over cycle planning.

\section{Weather's mattering: Air's force}

Attending to the medium through which movement happens is significant to understanding the experience of cycling. As Ingold notes, "the medium is rarely, if ever, still. Almost always, it is in a state of flux. Sometimes these fluxes are barely perceptible; at other times they are so strong that they can uproot trees and bring down buildings" (2007, p. S28). Such impacts of wind on cyclists' movements and how this could considerably affect their experiences of travel through Plymouth featured prominently in the interviews undertaken here (see Parkin et al, 2007). This is interesting as, to date, transport and mobilities research has been somewhat limited in its consideration of this specific manifestation of weather. In research on cycling still air is commonly assumed when it comes to assessing the efficiency and energy expended in moving and instead changes in relief are focused on as a key consistently 
measurable variable that impacts upon movement / momentum and so route suitability (Nixon, 2012). This is understandable though as in relatively still conditions air, "offering little resistance....allows us to move about...affords movement and perception" (Ingold, 2007, p. S25). Further, where wind has been considered this again has mostly been in quite limited terms. Here wind is taken as a barrier to cycling - it is attributed the capacity to impact on travel behavior by discouraging people from cycling. As such, wind's force is associated with impacts on why, how and when people move and not the content of what happens between A and B (see Helbich et al, 2014). However, as the participants in this study drew attention to, variations in atmospheric conditions do have significant implications for the way the environments moved through are experienced; there are more nuanced ways that wind becomes implicated with the experience of movement.

The cyclists interviewed here held a range of feelings about the impact of wind on their experience of cycling. For example, wind's capacities to impede progress came through in a number of discussions of how cycling in wind significantly increased the resistance faced in moving through the streets of Plymouth. Figure 3 (video version available here:

https://vimeo.com/228821859) shows an example of one cyclist's encounter with the wind as she cycled up onto The Hoe (a coastal green space to the south of the city centre). As the cyclist ascends to The Hoe she is increasingly exposed to the wind blowing onshore from the sea. Here the cyclist takes over 40 seconds to cover a distance of around $100 \mathrm{~m}$, moving barely quicker that the elderly pedestrian shown using a walking frame. The following morning the same stretch of path without wind was covered in approximately 25 seconds by the same cyclist. Echoing Spinney's (2006) discussion on exertion and ascent, interesting also is that throughout this section of the journey the cyclist alternates between looking down at the ground (due to the effort required to cycle here) and out to sea, where the wind is coming from. There is little visible evidence that wind is a problem in the still images here, though it can be heard distinctly on the video. Nonetheless, it is clear that she is aware of its origin and it being the source of her struggle; it significantly affected the cyclist at this point in her journey. Upon arrival at her place of work, she commented to another cyclist who had also just arrived that it was "a wicked wind" that day (Interviewee 16, Female, 30 [video]). 
Figure 3 'Wind on The Hoe'

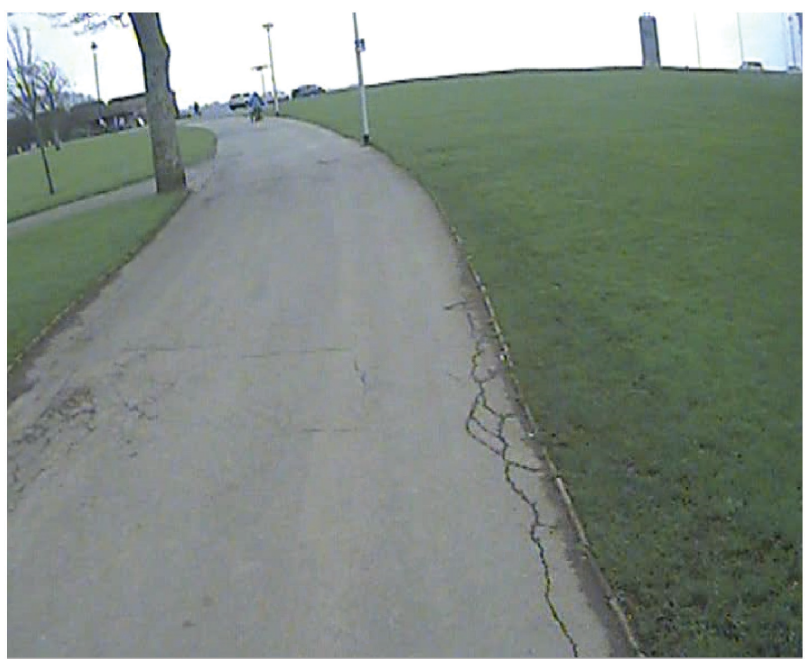

1) Approaching The Hoe

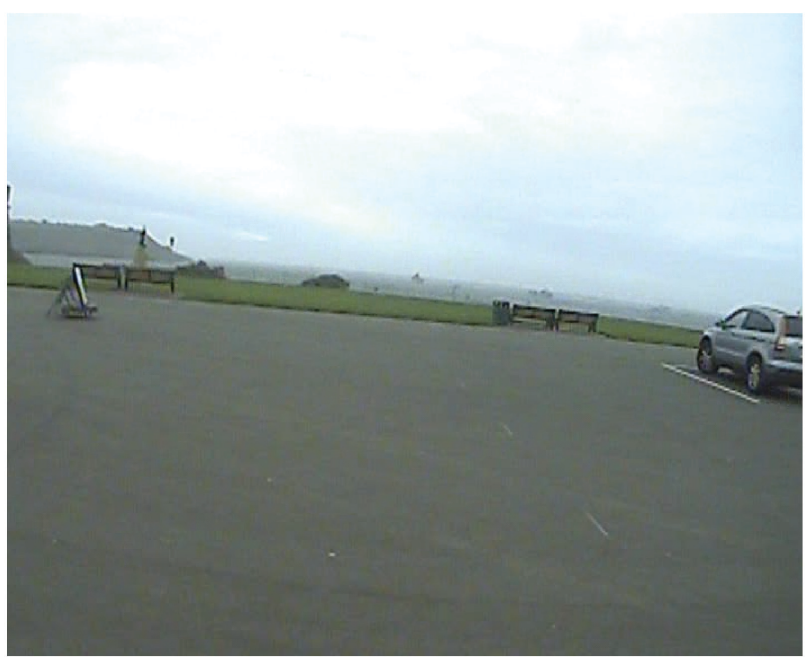

3) Looking out to sea for the source of the wind

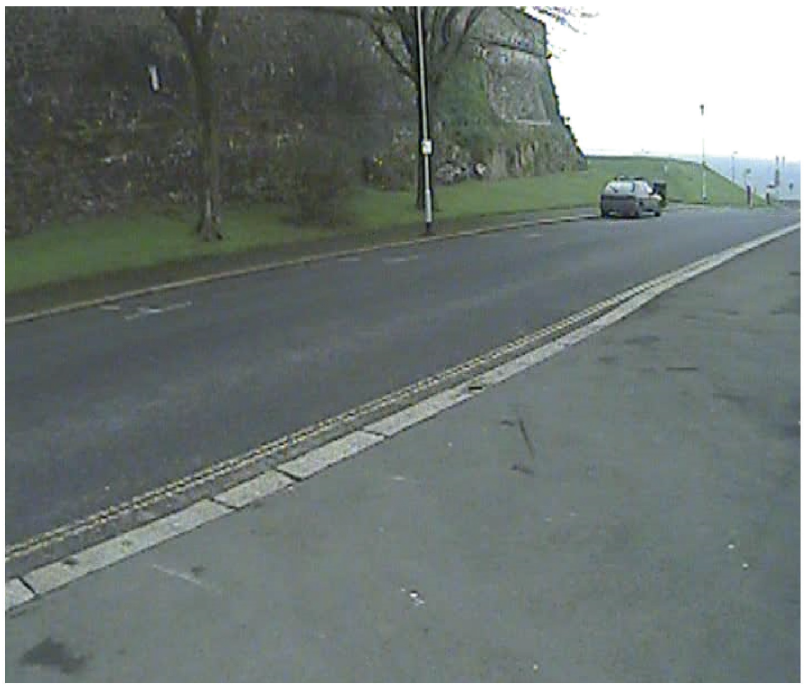

5) Re-enters the wind following brief respite when next to wall in Image 4

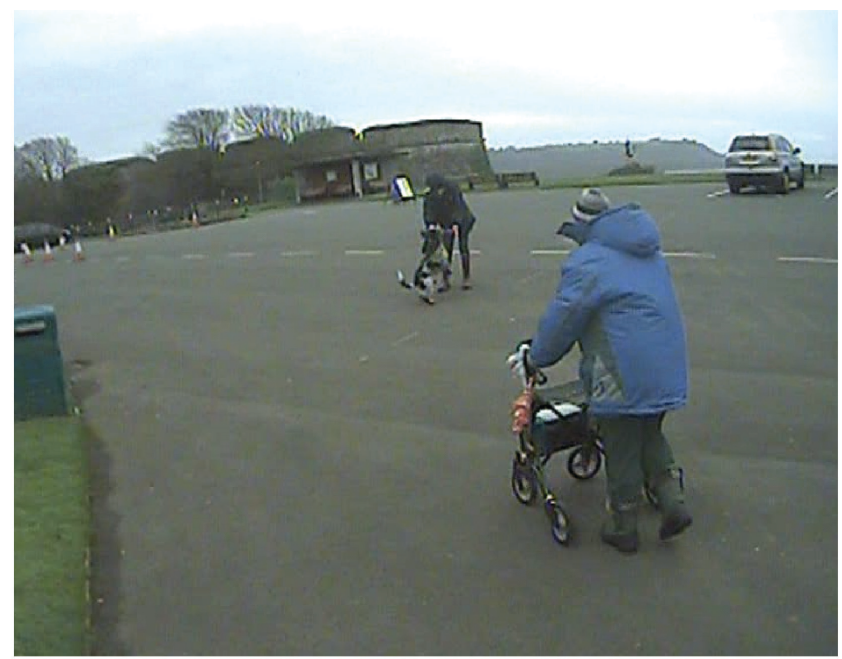

2) Slowly passing pedestrians

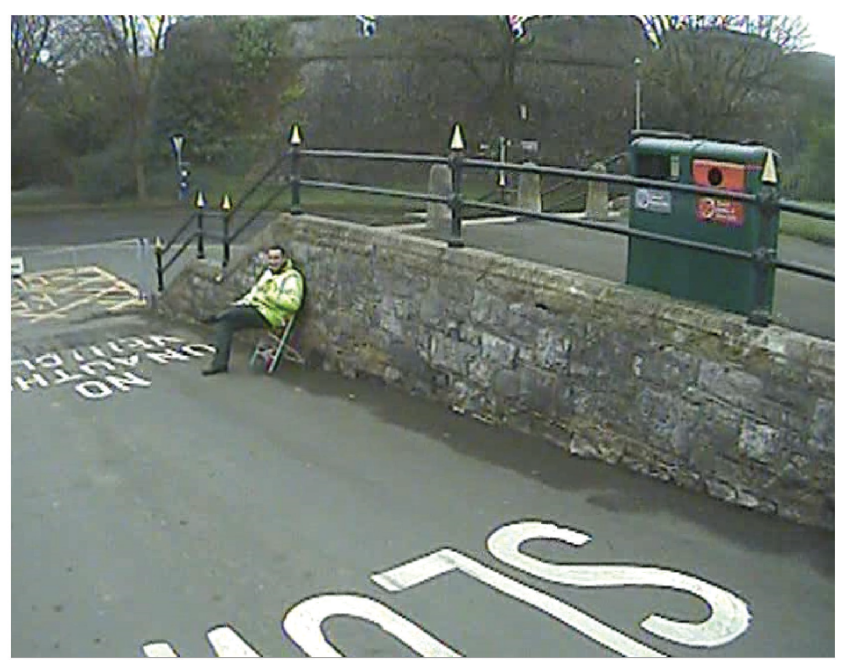

4) "Ah hah hah hah! Bloody hell that's strong! Ho!" (addressed to parking attendant)

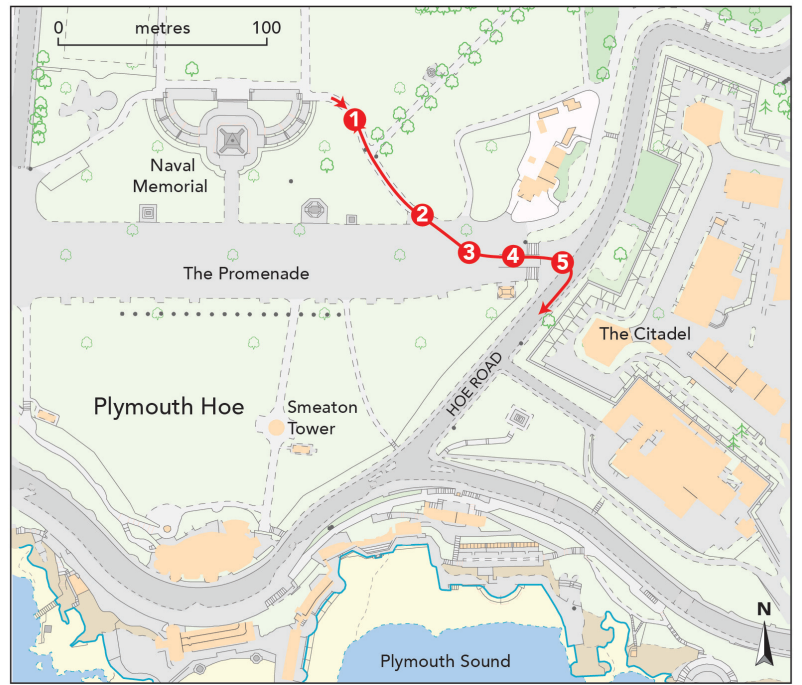

6) Route taken (Images 1-4 covered approx. 100m but took $40+$ seconds) 
Further, the impact of wind on cyclists and their ability to progress in their journey contrasts to some of the comments made about the hilly nature of Plymouth. While the effort of climbing a hill will generally be traded off against descent, wind here does not always provide such give-and-take. Rather, the geography of the city here acts to channel wind in a way that perpetually impeded these cyclists' capacities to move at pace. As one commented about moving on a north-south axis through the city:

"You get the katabatic wind that blows down...there's three valleys that come down...whatever the situation almost anywhere you always get a headwind." (Interviewee 22, Male, 61).

Katabatic winds, and their inverse anabatic winds, refer to the movement of wind down or up slopes, respectively, at different times of day depending on environmental factors such as temperature. As another elaborated:

"Well often there is...l cycle up in the morning and there's a head wind coming off the Moors, and then I cycle home in the evening or the late afternoon, and there's obviously a head wind coming off shore, you know, the other way. So it always seems to be...I can't ever think of a wind being with me, you know, a tail wind, it always seems to be a head wind, no matter which way l'm going...." (Interviewee 5, Male, 35).

Interesting here is the way that the wind produces additional resistance for the cyclist without any sort of respite. The cyclists' pace of movement may be steady rather than the stop and go / slow and fast rhythm that comes with elevation change (Nixon, 2012), but it is nonetheless felt to be laborious given the difficulty of maintaining a sense of momentum and the lack of respite from such wind. This was, in turn, felt in quite specific and at times nuanced ways. As another cyclist commented, showing a degree of hybrid embodiedtechnological knowledge and adaptation:

"Oh it can make a huge difference. When I used to cycle out to the mine, I used to work on the edge of Dartmoor, it would make a 3 or 4 gear difference, you know, the wind direction." (Interviewee 22, Male, 61).

In addition to this resistance that manifests through a headwind, some cyclists also commented on the challenges that come from cycling with a cross wind and the way that this could challenge their stability. This destabilizing became particularly disconcerting when cycling amid traffic and the sense of vulnerability this brought. For example, there are river valleys to the east and west of the city centre that bracket that area. The katabatic / anabatic winds mentioned above mean that there can be strong crosswinds from either direction when 
crossing these rivers on the way into and out of the city. As one cyclist explained in approaching the city from the east:

"when the wind whistles up...Cattedown Valley, you've got to be careful. And what I tend to do is I might cycle...probably another 6 or 7 inches out from the curb...normally I'm about a foot...but when it's conditions like that I'm around about 2 foot, because you suddenly get that gust, and within seconds you're into the curb. Now if I hadn't taken that extra sort of 5 or 6 inches I would be over that barrier." (Interviewee 1, Male, 63).

The opportunities afforded by such transport infrastructure varied, came to matter differently, as these atmospheric perturbations took effect and affected the cyclist. And as this quote highlights, such affectivity is enhanced by the invisible and potentially unanticipated arrival of a gust of wind as, for example, a corner is turned or an opening passed.

These examples illustrate the immediacy of these cyclists' encounters with the weather-world given the way that, for example, the wind literally buffets them, holds them in place, displaces them, and produces more physical exertion in their movement. Air here can quickly move from benign medium to something more pointedly encountered and affecting and back again as it becomes more or less turbulent, provides more or less resistance. In being attentive to this we need to think beyond just the 'things' that cyclists might encounter people, cars, buses, paths, and so on - to the turbulent and fluctuating media through which movement happens that also hold capacities to affect the cyclist and shape the ways that the furniture of their worlds appear for them. What a path does for a cyclist one day may appear very differently as the weather-world emerges differently on another. At the same time, the cyclists themselves are enrolled in such processes of emergence whereby their capacities to act and perceive evolve, their dispositions and habits are (re)shaped, as these various atmospheric conditions are encountered with each journey. Cyclists here adapted their practices in moving in such emerging atmospheric conditions in light of their knowledge of the changing affordances offered by different routes, certain surfaces, their bike's gears, and so on. They engaged in practices of 'weathering' by making "an environment familiar, at times adapting to it, at times cultivating an appreciation of it, at times hardly coping with it, but always regularly manipulating [their] own sensations" (Vannini et al, 2012, p. 377).

Such encounters between cyclist and infrastructural environment can be understood to be what McCormack calls 'circumstantial'. Thinking in terms of circumstance "provides a way of holding onto the consistency of partially enclosed entities [the coming together of cyclist and infrastructure, as well as cyclist and infrastructure themselves] that are never 
resolved into objects because they are always pulled and tugged out of shape by atmospheric deviations and fluctuations around them" (McCormack, 2014, p. 620). Such "turbulence produces new forms of complexity and thus...demands that we attend to the shifting interactions between the variegated forces of contemporary mobility" (Cresswell \& Martin, 2012, p. 517). From this "Circumstantial stories of atmospheric things emerge instead in the zone of exchange between turbulent, elemental materialities, and the apparently benign presence of self-contained, discrete things" (McCormack, 2014, p. 620). Or in other words, people and things, bodies and environments, weather and are weathered in the unfolding of these movements.

\section{Atmospheric materialities: Air qualities}

It needs to be remembered, though, that the turbulent medium through which movement happens still contains matter. Such materiality, in terms of the various particles that this air contains and is composed by, lies at a more micro-scale. While air may generally be thought of as being in some way 'immaterial', this is more a question of scale in perception (Sloterdijk, 2009). For example, we often forget that in smelling something we are actually taking in particles of that 'thing' into our bodies (Henshaw, 2014). Following Ingold's (2007) suggestion to redirect our attention beyond 'the congealed substances of the world' and 'the solid surfaces' they present us with towards the medium in which they take shape does not mean a turn away from matter. As McCormack (2007, p. 369) notes, "this materiality is a moving matter of relations, speeds, and slowness - a question of consistency, not concreteness". As such, this micro-scale matter poses questions about how we might recognize and attend to the materialities of the media we move through, how we might identify circumstances in which their affectivity becomes apparent (even if retrospectively), and how we might respond to this in terms of the forms our inhabitation of them takes.

Being amid such micro-scale materialities presented another way that cyclists highlighted their situation of exposure to the elements. A number of participants commented on being amid a range of fumes that emerge from the engines of those they shared the roads with. Depending on type, vehicle exhausts emit various quantities of nitrogen, oxygen, carbon dioxide, carbon monoxide, water vapor, nitrogen oxides, sulphur dioxide, hydrocarbons, and particulate matter into the air. Such exhaust fumes appear to present another phenomenon capable of intensifying "the immersive qualities of air" (Martin, 2011, p. 
456). Here the medium moved through began to take on further material consistency, with variously negative implications. As one cyclist noted:

"On very busy roads like Royal Parade, the traffic would be quite a discomfort because it's now so bad, because they always have these buses with running engine at bus stops...but then you really fell like you're biking through a cloud of toxic waste - which you are actually...it smells like bad and I tend to hold my breath, and I try to avoid it." (Interviewee 19, Female, 35).

This cyclist's reference to the toxicity of the fumes moved through and inhaled draws attention to an important point about such atmospheric emissions. Such atmospheric materiality produced through transportation has increasingly become a terrain of complex governance and debate (Marsden \& Rye, 2010). In the UK a range of policy responses seek to engage with and reduce vehicle emissions and so the composition of such atmospheres. For example, this has included the setting of targets for emissions levels from new vehicles and the variable taxation of vehicle depending on emission levels (i.e. vehicle excise duty). There was also the introduction of Local Sustainable Transport Funds (LSTF) for 77 local authorities to promote sustainable (i.e. low emission) forms of travel (Committee on Climate Change, 2013). Looking specifically at Plymouth's air quality and efforts to manage this, such mitigation efforts have included the recent award of nearly £500k from the Clean Vehicle Technology Fund to Plymouth City Council to pay for emissions reduction technology that is to be installed in 14 buses - specifically, regenerative breaking technologies that use energy generated when breaking to power lights and heating - that travel through key routes into and out of the city centre (Plymouth Newsroom, 2015). As mentioned earlier, these routes currently suffer from high levels of NO2 and fall within designated Air Quality Management Areas. That said, Plymouth does generally have good air quality and appears in the top 10 of recent rankings of cities with the lowest carbon emissions per capita (Plymouth City Council, 2011).

Despite such governance efforts and their impact (or not) on actual air particle content, the encounter discussed above was perceived by this cyclist in terms of its negative affects upon them: it produced discomfort. Such discomfort in turn led to acts that might limit that cyclist's capacity to act (holding her breath) and with that reduce her 'health', if understood in affective terms (i.e. that it reduced capacities to affect and act) (McCormack, 2007). That respiration entailed the consumption of various material elements suspended in the air - a rhythmic embodied act not normally perceived until it becomes 'arrhythmic' 
(Lefebvre, 2004), and a micro-scale materiality that often does not reach beyond the threshold of conscious awareness - became a focus of perception here is significant in itself. It some ways the presence of fumes here meant a 'rephenomenalization' of what might normally be aphenomenal (Sloterdijk, 2009). Here the force of air became felt not just as a result of its relative turbulence, but also given the (perceived) composition of that air itself.

From the cyclists included in this study, in addition to altering their route, some had experimented with forms of intermediary materials - what could be called 'atmotechnic innovations' (Sloterdijk, 2009) - to try to mediate their interaction with the fumes and so immunize themselves from the pervading qualities of such matter. One means of cyclists mediating their respiratory intake of such matter is to wear an anti-pollution cycling mask. Wearing such masks has been shown to have positive cardiovascular impacts during exposure to polluted air (Langrish et al, 2009). Equally though, such masks do not necessarily mediate cyclists' interactions with all such pollutants, either through a poor fit (so allowing particles in) or due to the very small size of some particles which means they can pass through the mask's filter (Godlee, 1990). For one cyclist in this study, and echoing common complaints with pollution masks, the use of such a mask was deemed to have limited success:

"I did used to pedal along with one of these little carbon masks, but in the summer it got so...you were just stifled, you couldn't get any fresh air, so I binned that. So there is a worry that some vehicles do really puff out some fumes...others are generally quite acceptable. But I think buses are the worst. I think where they run on this diesel fuel or this biofuel - I think that's the way they're running now - but in the past I come up behind buses and some lorries that really chuck out a black cloud. Ffff [exhales loudly]...all you do is just turn your head and hold your breath basically until that cloud has passed." (Interviewee 1, Male, 63).

A common theme from these last two quotes from cyclists is their reference to buses. These were often identified as presenting an issue when it came to fumes in being some of the worst producers. This exposure to bus fumes was also tied up with specific forms of infrastructural provision for cyclists in Plymouth used by cyclists in this study: bus lanes that are also designated for use by cyclists (as well as motorbikes and taxicabs). In addition to concerns generally over being in proximity to buses in these spaces given the extreme difference in size between cyclists and buses (see Jones, 2005), another issue with the sharing of such spaces came in terms of the inability often to get past buses and how cyclists 
could end up caught behind or amongst them and their progress interrupted by their constant stopping. As one cyclist elaborates:

"they [buses] go about the same speed [as cyclists], cos they zoom past you and then they stop...Y You tend to sort of you know...you can have that unfortunate situation where you're both going on the same road at the same time and you never quite get clear of them. You're constantly overtaking and being overtaken by the bus." (Interviewee 2, Female, 36).

Such perpetual overtaking and generally being stuck amongst buses then can act to perpetuate the cyclist's exposure to the fumes that emanate from them. Further, this often entailed being around these buses at points where their emissions will be highest - such emissions often emanate most voluminously when buses pull off or accelerate (see Figure 4 [and the video-based version here: https://vimeo.com/228824730]). ${ }^{4}$ This immersion within and experience of the materiality of the atmosphere, as well as the cyclist's experience of the broader 'weather-world', happens contextually. These interactions are staged, for example, by the specific transport infrastructure present given the way that such infrastructure bring together a variety of differently mobile bodies, bodies moving at differing degrees of speed and slowness, of acceleration and pausing, and so amid varying levels of micro-scale materiality that come to be present at any given point within such encounters (see Simpson, 2017; Latham \& Wood, 2015 for a further discussion of the experience of transport infrastructure).

For many cyclists interviewed here such exposure was not deemed to be problematic enough to impact upon their overall decision to cycle. It was felt that the implication of the materiality of the fumes and their body was not of sufficient detriment when balanced with the fitness produced through their more general cycling practices in cleaner air. As one cyclist noted:

"I mean, obviously there must be a fair bit of ambient pollution, given the nature of the roads, but no it doesn't really... know there's stuff in there that I'm breathing in which isn't very good for you - but I guess it's the balance between that and the fitness I'm gaining from cycling" (Interviewee 21, Male, 46).

Again, we can see here how health can be understood in affective terms (McCormack, 2007). The capacities for such ambient pollution to affect the cyclist's capacities to act or the 'health' of the cycling body was deemed lesser than the positive affects of the exercise - the fitness that comes from the act of cycling itself - on that body's capacities. 
Figure 4 'Trying to pass a bus in traffic'

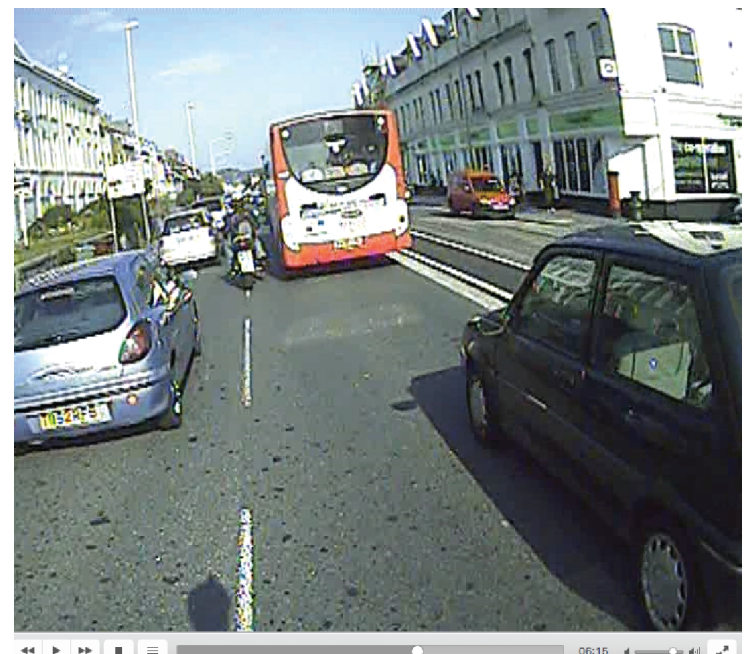

1) The cyclist here is approaching a bus while filtering between two lanes of stop-start traffic

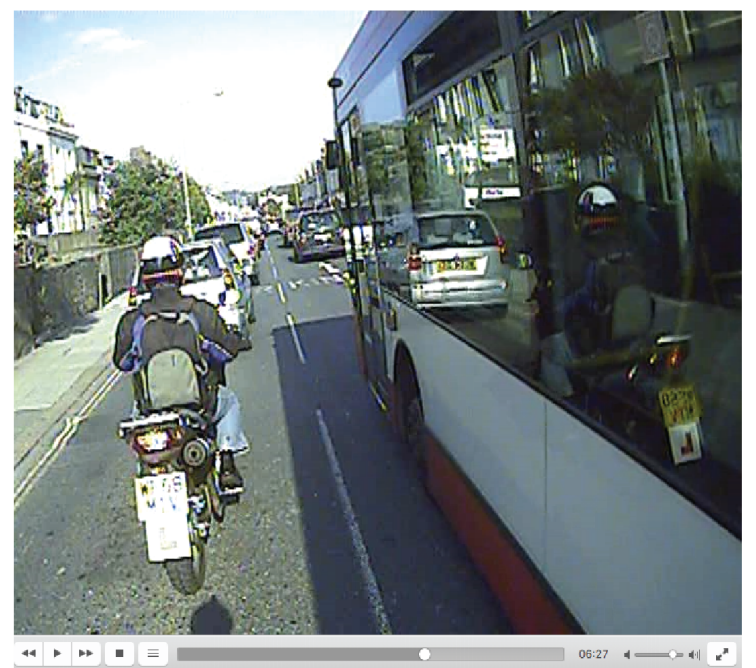

3) A further six seconds later, the cyclist has reached half way up the bus's side

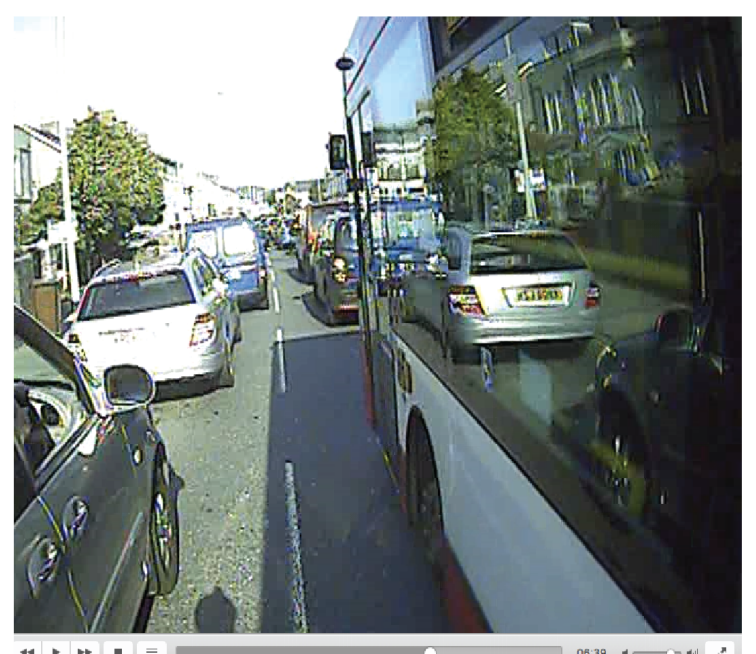

5) A further five seconds later the bus has slowed again and the cyclist again has reached half way up the bus's side

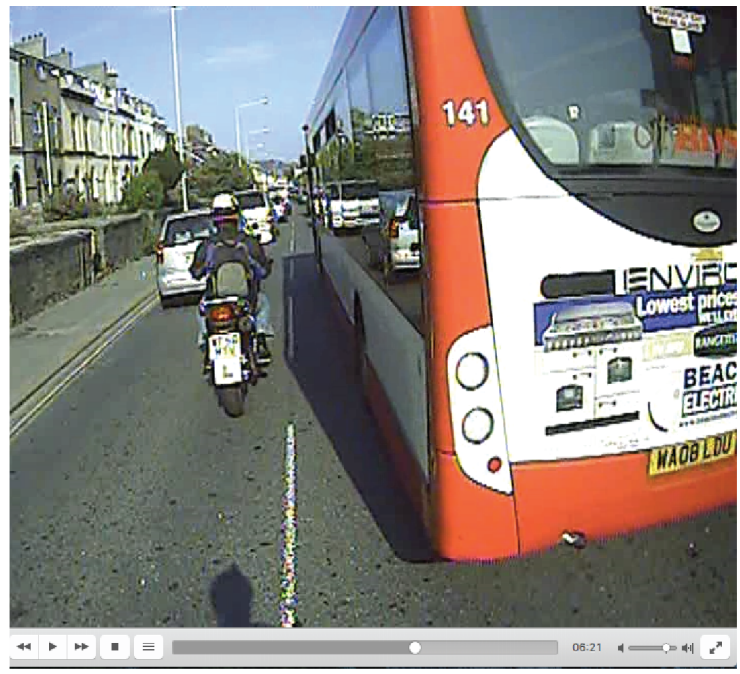

2) Six seconds later the cyclist has caught up with the bus

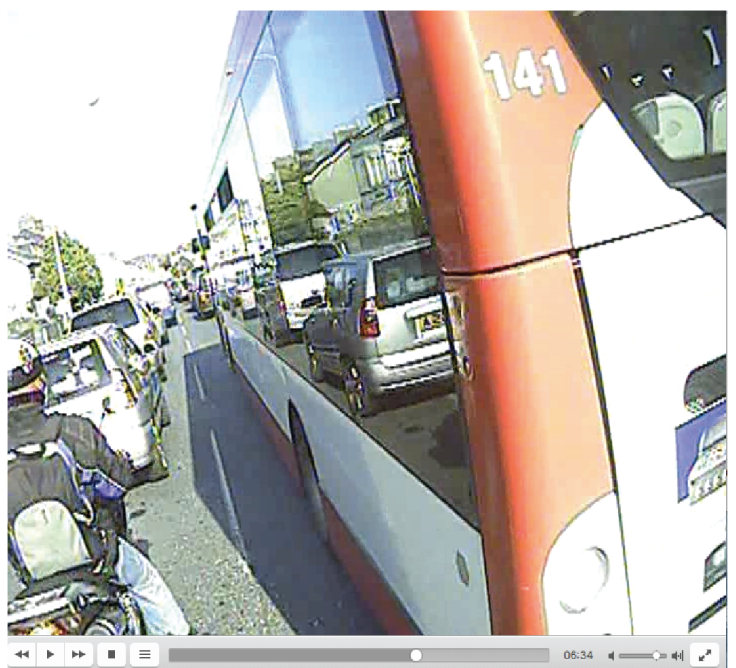

4) Seven seconds later the bus has accelerated and pulled back ahead of the cyclist

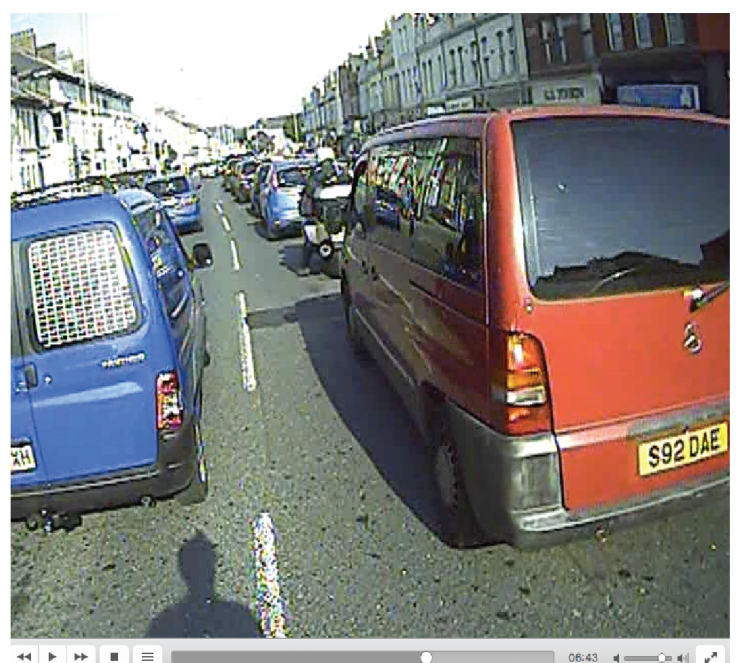

6) Four seconds later (and 22 since first reaching it) the cyclist is clear of the bus 
A comment made by this cyclist immediately following the quote above also returns us to the point that such fumes do not necessarily exist suspended in a static medium, but rather are caught up in the sort of perturbations in the weather-world discussed earlier. This cyclist went on to note that:

"if the wind is blowing like it quite often is as well, that must disperse it pretty darned quick. It's a lovely ride in actually when the tide's in as well and the sun's shining" (Interviewee 21, Male, 46).

When considering the micro-scale materialities that exist in the atmosphere and which come to be experienced by various mobile bodies, it needs to be remembered that such materialities are constantly in movement (McCormack, 2007). The air that these particles are suspended in is rarely still; "neither those who emit particulate, the winds that carry it, nor those who breathe it sit still in places" (Choy, 2012, p. 142). They do not present us with static, 'congealed', solid objects, but rather as things that flow, swirl, rise and fall, carried by variously scaled changes in respiration, metabolism, weather, season, climate, and so on. Such movements are in turn contextual, influenced by both the bodies that move through them but also, for example, emerge from in the midst of the micro-climatic variations that various urban forms can encourage or bring about (Helbich et al, 2014).

\section{Conclusion}

This paper has developed social and cultural geography's considerations of the experience of movement by considering how various atmospheric circumstances make and remake both mobile environments and mobile subjectivities. In doing so, the paper has built upon previous work in transport geography which has engaged with the impacts of, for example, weather on travel behaviour to consider more the experience of moving through such atmospheric circumstances. At the same time, it has also contributed to nascent developments in recent work in social and cultural geography that question geography's elemental prejudices and related conceptions of materiality by expanding the sorts of materialities considered when it comes to everyday mobility. In pursuing this, the paper has considered such atmospheric geographies in a way that recognizes their multi-sided nature - that these are meteorological, material, and felt / affective - and that these different atmospheric or elemental senses are interrelated and interrelate (Ingold, 2015). 
Based on the examples of air's force and varied air quality discussed in this paper, the lack of mediation between cyclists and the environments they move through comes to prominence. In this we can see the capacities of variably turbulent air to order and disorder experience, to be a fundamental and ever-present force within mobile experiences and not just a secondary or exceptional phenomenon (Cresswell \& Martin, 2012). There is a general and literally pervasive connectedness between person and environment in terms of the agential action of wind on body or even through this environment entering into, and to potentially settle in, the body of the cyclists. What Choy calls "the co-productive engagements between people and air" draws attention to the "tactility of the atmosphere" (2012, p. 139). In this, "Air muddies the distinction between subjects and environments, and between subjects" (Choy, 2012, p. 139). This in turn shapes the cyclist's capacities to move, their experience of being on the move, and their perceptions of the environments they move through.

Amongst all of this, a key challenge has persisted: how might we (as academics or those interested in planning for mobility) become better attuned to such environmental circumstances? It is by no means easy approach how "capacities are transformed, however subtly, by the experiences that bodies have and the spaces in which these experiences take place" (Bissell, 2016, p. 401). In the context of transport planning, while increasingly the agendas of transport planning evolve around the implementation of infrastructure that seeks to promote use and, within that, produce 'civilized spaces' (Department for Transport, 2016), it is clear that such approaches are premised on quite narrow conceptions of what such positive circumstances might be composed by. As such, trying to be more attentive to this atmospheric weather-world in the context of practices like cycling - from the perspectives of both researching it and planning for it - means developing an appreciation of the capability of bodies to affect and be affected by the full extent of their environments, and especially by those forces of which we are not always immediately aware.

\section{References}

Adey, P. (2014). Air: Nature and Culture. London: Reaktion.

Adey, P. (2015). Air's affinities: Geopolitics, chemical affect and the force of the elemental. Dialogues in Human Geography, 5, 54-75. 
Adey, P., Anderson, B. \& Lobo-Guerrero, L. (2011). An ash cloud, airspace and environmental threat. Transactions of the Institute of British Geographers, 36, 338-343.

Adey, P., Bissell, D., Hannam, K., Merriman, P. \& Sheller, M. (Eds). (2014). The Routledge Handbook of Mobilities. London: Routledge.

Adey, P., Brayer, L., Masson, D., Murphy, P., Simpson, P. \& Tixier, N. (2013). 'Pour votre tranquillité': ambiance, atmosphere, and surveillance. Geoforum, 49, 209-309.

Aldred, R. (2010). 'On the outside': constructing cycling citizenship. Social and Cultural Geography, 11, 35-52.

Aldred, R. (2012). Governing transport from welfare state to hollow state: The case of cycling in the UK. Transport Policy, 23, 95-102.

Aldred, R. (2013a). Incompetent or Too Competent? Negotiating Everyday Cycling Identities in a Motor Dominated Society. Mobilities, 8, 252-271.

Aldred, R. (2013b). Who are Londoners on Bikes and what do they want? Negotiating identity and issue definition in a 'pop-up' cycle campaign. Journal of Transport Geography, 30, 194201.

Anderson, B. \& Wylie, J. (2009). On geography and materiality. Environment and Planning A, 41, 318-335.

Bissell, D. (2016). Micropolitics of Mobility: Public Transport Commuting and Everyday Encounters with Forces of Enablement and Constraint. Annals of the Association of American Geographers, 106, 394-403.

Böcker, L., Dijst, M. \& Prillwitz, J. (2013). Impact of Everyday Weather on Individual Travel Behaviours in Perspective: A Literature Review. Transport Reviews, 33, 71-91 
Böcker, L., Dijst, M., Faber, J. \& Helbich, M. (2015). En-route weather and place valuations for different transport mode users. Journal of Transport Geography, 47, 128-138.

Bohme, G. (2016). The Aesthetics of Atmospheres. London: Routledge.

Choy, T. (2012). Air's Substantiations. In Sunder Rajan, K. (Ed) Lively Capital: Biotechnologies, Ethics, and Governance in Global Markets (pp. 121-152). London: Duke University Press.

Committee on Climate Change (2013). Factsheet: Transport. Retrieved from: https://www.theccc.org.uk/publication/transport-factsheet/

Cresswell, T. \& Martin, C. (2012). On Turbulence: Entanglements Of Disorder And Order On A Devon Beach. Tijdschrift voor Economische en Sociale Geografie, 103, 516-529.

Department for Transport (2016). Cycling and Walking Investment Strategy. Retrieved from: https://www.gov.uk/government/consultations/draft-cycling-and-walking-investment-strategy.

Godlee, F. (1990). Cycling Masks: How Effective?. BMJ, 301, 508.

Helbich, M., Böcker, L, \& Dijst, M. (2014). Geographic heterogeneity in cycling under various weather conditions: evidence from Greater Rotterdam. Journal of Transport Geography, 38, 38-47.

Henshaw, V. (2014). Urban Smellscapes: Understanding and Designing City Smell Environments. London: Routledge.

Ingold, T. (2007). Earth, sky, wind, and weather. Journal of the Royal Anthropological Institute (N.S.), S19-S38. 
Ingold, T. (2008). Bindings against boundaries: entanglements of life in an open world. Environment and Planning A, 40, 1796-1810.

Ingold, T. (2015). The Life of Lines. London: Routledge.

Jackson, M. \& Fannin, M. (2011). Letting geography fall where it may - aerographies address the elemental. Environment and Planning D: Society and Space, 29, 435-444.

Jones, P. (2005). Performing the city: a body and a bicycle take on Birmingham, UK. Social and Cultural Geography, 6, 813-830.

Jones, P. (2012). Sensory indiscipline and affect: a study of commuter cycling. Social \& Cultural Geography, 13, 645-658.

Jungnickel, K. \& Aldred, R. (2014). Cycling's Sensory Strategies: How Cyclists Mediate their Exposure to the Urban Environment. Mobilities, 9, 238-255.

Langrish, JP., Mills, NL., Chan, JKK., Leseman, DLAC., Aitken, RJ., Fokkens, PHB., Cassee, FR., Li, J,. Donaldson, K., Newby, DE. \& Jiang, L. (2009). Beneficial cardiovascular effects of reducing exposure to particulate air pollution with a simple facemask. Particle and Fibre Toxicology, 8.

Latham, A. \& Wood, PRH. (2015). Inhabiting infrastructure: exploring the interactional spaces of urban cycling. Environment and Planning A, 47, 300-319.

Lefebvre, H. (2004). Rhythmanalysis. London: Continuum.

Marsden, G. \& Rye, T. (2010). The governance of transport and climate change. Journal of Transport Geography, 18, 669-678.

Martin, C. (2011). Fog-bound: areal space and the elemental entanglements of body-withworld. Environment and Planning D: Society and Space, 29, 454-468. 
McCormack, D. (2007). Molecular affects in human geographies. Environment and Planning A, 39, 359-377

McCormack, D. (2008). Engineering affective atmospheres on the moving geographies of the 1897 Andree expedition. Cultural Geographies, 15, 413-430

McCormack, D. (2014). Atmospheric things and circumstantial excursions. Cultural Geographies, 21, 605-625.

Merriman, P. (2012). Mobilities, Space and Culture. London: Routledge.

Nixon, DV. (2012). A sense of momentum: mobility practices and dis/embodied landscapes of energy use. Environment and Planning A, 44, 1661-1678.

Parkin, J., Ryley, T. \& Jones, T. (2007). Barriers to Cycling: An Exploration of Quantitative Approaches. In Horton, D., Rosen, P. \& Cox, P. (Eds) Cycling and Society (pp. 67-82). Aldershot: Ashgate.

Plymouth City Council (2011). Local Transport Plan: 2011-2026. Retrieved from: http://www.plymouth.gov.uk/ltp.

Plymouth City Council (2016). Air Quality Annual Status Report - August 2016. Retrieved from:

https://www.plymouth.gov.uk/sites/default/files/AirQualityAnnualStatusReportSummary2016. pdf.

Plymouth Cycle Campaign (n.d.). A Bridge Linking Central Park to Central Plymouth Retrieved from: https://plymouthcyclingcampaign.co.uk/a-bridge-linking-central-park-tocentral-plymouth/ 
Plymouth Newsroom (2015). Cleaner, greener technology for Plymouth buses. Retrieved from: http://plymouthnewsroom.co.uk/cleaner-greener-technology-plymouth-buses/

Simpson, P. (2017). A sense of the cycling environment: felt experiences of infrastructure and atmospheres. Environment and Planning A, 49, 426-447.

Skinner, D. \& Rosen, P. (2007). Hell is Other Cyclists: Rethinking Transport and Identity. In Horton, D., Rosen, P. \& Cox, P. (Eds) Cycling and Society (pp. 83-96). Aldershot: Ashgate.

Sloterdijk, P. (2009). Terror from the air. Los Angeles: Semiotext(e).

Spinney, J. (2006). A place of sense: a kinaesthetic ethnography of cyclists on Mont Ventoux. Environment and Planning D: Society and Space, 24, 709-732.

Spinney, J. (2007). Cycling the City: Non-Place and the Sensory Construction of Meaning in a Mobile Practice. In Horton, D., Rosen, P. \& Cox, P. (Eds) Cycling and Society (pp. 25-46). Aldershot: Ashgate.

Spinney, J. (2011). A chance to catch a breath: Using mobile video ethnography in cycling research. Mobilities, 6, 161-182.

Tonkiss, F. (2015). Afterword: Economies of infrastructure. City, 19, 384-391.

Vannini, P., Waskul, D., Gottschalk, S. \& Ellis-Newstead, T. (2012). Making Sense of the Weather: Dwelling and Weathering on Canada's Rain Coast. Space and Culture, 15, 261380.

Veale, L., Endfield, G. \& Naylor, S. (2014). Knowing weather in place: the Helm Wind of Cross Fell. Journal of Historical Geography, 45, 25-37.

\section{Notes}


${ }^{1}$ See: http://www.plymouthherald.co.uk/plans-unveiled-new-bridge-link-plymouth-city/story-28715256detail/story.html and https://www.facebook.com/groups/PlymouthCyclingCampaign/

${ }^{2}$ See http://www.metoffice.gov.uk/learning/wind/windiest-place-in-UK

${ }^{3}$ The majority of the cyclists included were aged between 30 and 50, with a gender split of 13 men and 11 women. All cyclists had cycled in Plymouth for at least 2 years and normally commuted by bike 2-3 times per week as well as cycling recreationally.

${ }^{4}$ This situation is changing, primarily given the introduction of hybrid engines in buses in some places (such as London). However, at the time of writing, such hybrid buses are not found in Plymouth. 